\title{
Evaluation of the American Society of Cataract and Refractive Surgery intraocular lens calculator for eyes with prior radial keratotomy
}

This article was published in the following Dove Press journal:

Clinical Ophthalmology

30 August 201I

Number of times this article has been viewed

\author{
David L DeMill \\ Maylon Hsu \\ Majid Moshirfar \\ John A Moran Eye Center, University \\ of Utah, Salt Lake City, UT, USA
}

Background: The purpose of this study was to evaluate the American Society of Cataract and Refractive Surgery (ASCRS) intraocular lens (IOL) calculator for eyes with prior radial keratotomy and assess the accuracy of its methods in predicting IOL power in patients with previous radial keratotomy.

Methods: This retrospective study included data from 15 eyes with previous radial keratotomy and subsequent cataract surgery. The average central power and Humphrey Atlas methods from the ASCRS IOL calculator, along with an average IOL power produced from an average of these two methods (ASCRS average), were compared. Primary outcome measures for each method were mean arithmetic and absolute IOL prediction error, variance in mean arithmetic IOL prediction error, and the percentage of refractive outcomes within $\pm 0.50, \pm 1.00, \pm 1.50$, and \pm 2.00 diopters (D).

Results: The average central power method and the ASCRS average were significantly more accurate than the Humphrey Atlas method in terms of mean absolute IOL prediction error (1.03 D and $1.02 \mathrm{D}$ versus $1.53 ; P=0.04$ and $P=0.01$, respectively). In addition, the average central power method and ASCRS average produced a higher percentage of refractive outcomes within \pm 0.50 D when compared with the Humphrey Atlas method (60\% and $46.67 \%$ versus $0 \%$, respectively). A comparison of the average central power method and the ASCRS average demonstrated a smaller variance and higher percentage of patients within $\pm 1.00 \mathrm{D}$ when using the ASCRS average.

Conclusion: The ASCRS calculator for eyes with prior radial keratotomy is an easily accessible and valuable online tool for calculating IOL power in patients with previous radial keratotomy. We found that the ASCRS average produced by the calculator provided the best IOL prediction. We recommend using it with the addition of 1.00 to $1.50 \mathrm{D}$ to its IOL power prediction.

Keywords: radial keratotomy, cataract, intraocular lens calculator, American Society of Cataract and Refractive Surgery

\section{Introduction}

The use of radial keratotomy has diminished since the advent of laser-assisted in situ keratomileusis (LASIK) and photorefractive keratectomy (PRK), which are both more accurate and predictable in correcting refractive error than radial keratotomy. ${ }^{1}$ However, an estimated 1.2 million people underwent radial keratotomy between 1980 and $1990,{ }^{2,3}$ many of whom will eventually require cataract surgery. Studies ${ }^{4,5}$ have shown that refractive outcomes after cataract surgery in such patients are very challenging to predict, because radial keratotomy alters corneal curvature, leading to errors when measuring the central corneal power $^{6}$ and estimating effective lens position. ${ }^{5}$
Correspondence: Majid Moshirfar John A Moran Eye Center, 65 Mario Capecchi Drive, Salt Lake City, UT 84I32, USA

Tel + I 80I 58I 2352

Fax + I $80158 \mid 3357$

Email majid.moshirfar@hsc.utah.edu 
Both of these errors lead to an underestimation of the predicted intraocular lens (IOL) power, leaving the patient hyperopic. $^{\text {? }}$

Fortunately, the effective lens position can now be better estimated using third-generation and fourth-generation IOL formulae. ${ }^{8,9}$ Newer biometry devices ${ }^{5,10-12}$ have also increased the accuracy of central corneal power measurements. The American Society of Cataract and Refractive Surgery (ASCRS) IOL calculator for eyes with prior radial keratotomy ${ }^{11}$ incorporates several of these advances in effective lens position and central corneal power estimation. The goal of this study is to evaluate the ASCRS IOL calculator to determine its accuracy of IOL prediction in eyes with previous radial keratotomy.

\section{Methods}

A retrospective chart review was conducted of patients with previous radial keratotomy and subsequent cataract surgery from March 2008 to April 2011 performed by one surgeon $(\mathrm{MM})$ at the John A Moran Eye Center. Cataract surgeries were performed using $2.2 \mathrm{~mm}$ temporal clear corneal incisions and the Alcon Infiniti phacoemulsification system (Alcon Laboratories, Fort Worth, TX). A Tecnis ZCB00, Tecnis Z9002, Tecnis ZA9003 (all from Abbot Medical Optics, Abbott Park, IL), AcrySof IQ SN60WF or AcrySof SA60AT (both from Alcon Laboratories) IOL was used for implantation into the capsular bag.

All data requested by the ASCRS IOL calculator for eyes with prior radial keratotomy were required for study inclusion, with the exception of the value requested from the EyeSys 3000 Corneal Atlas System, which was not used in our precataract evaluations. The average central corneal power was obtained from the Pentacam (Oculus Inc, Wetzlar, Germany) equivalent keratometry reading at a $4.5 \mathrm{~mm}$ optimal zone, as described by Holladay et al. ${ }^{12}$ Keratometry measurements at the 1-4 mm zone were measured with the Humphrey Atlas (Carl Zeiss Meditec, Dublin, CA). Axial length measurements were recorded from the IOL Master v4 (Carl Zeiss Meditec). Exclusion criteria included major complications during or after cataract surgery and missing data required by the calculator.

The ASCRS IOL calculator uses the Aramberri double-K modification of the Holladay 1 formula and produces values from the average central power, Humphrey Atlas 1-4, and EyeSys effective refractive power methods. An average IOL power (ASCRS average) is also produced from an average of all methods available from the calculator. In this study, the ASCRS average consisted of the average of the Humphrey Atlas and average central power methods.
Using the ASCRS IOL calculator, with optimized lens constants for the surgeon (MM) and targeting at the actual refraction recorded after cataract surgery, the predicted IOL power for each method was obtained. The IOL prediction error was then determined by subtracting the predicted IOL power from the power of the IOL implanted. ${ }^{13}$ Thus, a positive value indicates that method predicts an IOL of less power than the power of the implanted IOL, leaving the patient hyperopic.

The following results were evaluated for each method studied: mean arithmetic IOL prediction error; mean absolute IOL prediction error; variance in mean arithmetic IOL prediction error; and percentage of eyes within a certain refractive prediction error. Using the assumption that 1.00 diopter (D) of IOL prediction error produces $0.70 \mathrm{D}$ of refractive error at the spectacle plane, the percentage of eyes within a refractive error of \pm 0.50 (IOL prediction error \pm 0.71 ), \pm 1.00 (IOL prediction error \pm 1.43 ), \pm 1.50 (IOL prediction error \pm 2.14 ), and \pm 2.00 (IOL prediction error \pm 2.86 ) were computed for each method. ${ }^{13,14}$

\section{Statistical analysis}

Statistical analysis was performed using STATA data analysis and statistical software (Release 11. StataCorp LP, College Station, TX). Two-sample paired $t$-tests with equal variances were done to compare the mean arithmetic and absolute IOL prediction errors. The F-test for variance was utilized to compare the consistency of the different prediction values and the McNemar test was used to compare the percentages of eyes ending up within a certain refractive prediction error. A linear regression analysis was performed to investigate what influence the number of radial keratotomy incisions had on post-cataract refractive outcomes. The Hochberg correction was applied for multiple tests.

\section{Results}

The study consisted of 15 eyes from 10 patients. The patients included had a mean age of $63.53 \pm 3.22$ years, a mean number of radial keratotomy incisions of $10.13 \pm 3.66$, a mean precataract spherical equivalent of $0.04 \pm 3.88 \mathrm{D}$, mean pre-cataract Pentacam average central corneal power of $38.92 \pm 1.90 \mathrm{D}$, and a mean precataract Humphrey Atlas 1-4 average of $39.28 \pm 1.85$ D. (Table 1). Post-cataract data were obtained at an average of $4.33 \pm 3.70$ months after surgery. The worst best-corrected visual acuity after cataract surgery in this study was $20 / 25$. One patient had four radial keratotomy incisions, eight patients had eight radial keratotomy incisions, three patients had 12 radial keratotomy incisions, and three patients had 16 radial keratotomy incisions. 
Table I Patient demographics

\begin{tabular}{lcl}
\hline $\mathbf{N}=$ I5 eyes & $\begin{array}{l}\text { Mean } \pm \text { standard } \\
\text { deviation }\end{array}$ & Range \\
\hline Age at cataract surgery (years) & $63.53 \pm 3.22$ & 58 to 68 \\
Pre-cataract surgery SE (D) & $0.04 \pm 3.88$ & -7.25 to 6.13 \\
$\begin{array}{l}\text { Pre-cataract surgery pentacam } \\
\text { average }\end{array}$ & $38.92 \pm 1.90$ & 34.50 to 42.00 \\
$\begin{array}{l}\text { Central corneal power (D) } \\
\text { Pre-cataract surgery }\end{array}$ & \\
Humphrey Atlas & $39.28 \pm 1.85$ & 34.27 to 42.55 \\
I-4 mm average (D) & & \\
Axial length (mm) & $25.5 I \pm 0.69$ & 24.69 to 26.97 \\
IOL power (D) & $22.47 \pm 3.24$ & 18.00 to 30.00 \\
Number of RK incisions & $10.13 \pm 3.66$ & 4 to 16 \\
\hline
\end{tabular}

Abbreviations: SE, spherical equivalent; D, diopters; IOL, intraocular lens.

The average central power method and the ASCRS average were more accurate in the majority of outcome indicators than the Humphrey Atlas method (Tables 2 and 3). The average central power method and ASCRS average had significantly smaller mean absolute IOL prediction errors (1.03 D and 1.02 $\mathrm{D}$, respectively) than the Humphrey Atlas method (1.53 D, $P=0.04$ and $P=0.01$, respectively). The average central power method and ASCRS average both resulted in a significantly higher percentage of outcomes within $\pm 0.50 \mathrm{D}$ when compared with the Humphrey Atlas method (60\% and $46.67 \%$ versus $0 \%$, respectively, $P=0.004$ and $P=0.02$, respectively).

Although not statistically significant, the average central power method and ASCRS average also had smaller mean arithmetic IOL prediction errors (Figure 1), ranges, and variances while producing a higher percentage of outcomes within $\pm 1.00 \mathrm{D}$ than the Humphrey Atlas method. There were two outliers in the mean arithmetic IOL prediction errors when using the Humphrey Atlas method. Removing these outliers from the Humphrey Atlas method analysis increased the mean arithmetic IOL prediction error from 1.07 D to $1.50 \mathrm{D}$ and decreased the standard deviation from $1.30 \mathrm{D}$ to $0.69 \mathrm{D}$.

When comparing the average central power method and the ASCRS average, the findings observed were not statistically significant. The average central power had a smaller mean IOL prediction error $(0.54 \mathrm{D}$ versus $0.81 \mathrm{D}$, respectively) and a higher percentage of outcomes within $\pm 0.50 \mathrm{D}$ ( $60 \%$ versus $46.67 \%$, respectively). However, the ASCRS average had a smaller variance (1.19 versus 1.65 , respectively) and a higher percentage of outcomes within $\pm 1.00 \mathrm{D}(66.67 \%$ versus $60 \%$, respectively).

\section{Discussion}

The poor predictability of post-cataract refractive outcomes in patients with prior radial keratotomy remains a frustrating issue. Fortunately, outcomes are improving with new technology that increases accuracy of central corneal power measurements and effective lens position estimation. Recent studies by Packer et $\mathrm{al}^{5}$ and Awwad et $\mathrm{al}^{10}$ utilized this technology in evaluating IOL calculations in patients with previous radial keratotomy. However, both studies either relied on technology not readily available to most ophthalmologists or used lengthy formulae. The method used in the Packer et al study relied on both the Holladay 2 formula, only available as part of the Holladay IOL Consultants Software, and the effective power parameter, obtained with the EyeSys 3000 Corneal Atlas. The Awwad et al study used the same third-generation formula as the ASCRS IOL calculator, with measurements from the Topographic Modeling System (Tomey Corporation, Nagoya, Japan).

The ASCRS IOL calculators, ${ }^{15}$ on the other hand, are accessible online for all ophthalmologists and are very easy to use. There are three ASCRS IOL calculators, ie, one for eyes with prior myopic LASIK/PRK, one for eyes with prior hyperopic LASIK/PRK, and one for eyes with prior radial keratotomy. The ASCRS IOL calculator for eyes with prior myopic LASIK/PRK has been thoroughly studied and is widely utilized. ${ }^{13}$ To date, there have been no studies evaluating the results of the ASCRS IOL calculators for eyes with prior hyperopic LASIK/PRK or radial keratotomy. ${ }^{13}$ We report the first published outcomes of the ASCRS IOL calculator for eyes with prior radial keratotomy.

Table 2 IOL prediction error and variance for each method

\begin{tabular}{|c|c|c|c|c|c|}
\hline & \multicolumn{5}{|c|}{ IOL prediction error } \\
\hline & $\begin{array}{l}\text { Arithemetic } \\
\text { mean } \pm \text { SD (D) }\end{array}$ & $\begin{array}{l}\text { Arithmetic } \\
\text { range (D) }\end{array}$ & $\begin{array}{l}\text { Absolute } \\
\text { mean } \pm \text { SD (D) }\end{array}$ & $\begin{array}{l}\text { Absolute } \\
\text { range (D) }\end{array}$ & Variance \\
\hline $\begin{array}{l}\text { Average } \\
\text { central power }\end{array}$ & $0.54 \pm 1.28$ & -1.54 to 2.72 & $1.03 \pm 0.92$ & 0.13 to 2.72 & 1.65 \\
\hline $\begin{array}{l}\text { Humphrey } \\
\text { Atlas I-4 }\end{array}$ & $1.07 \pm 1.30$ & -1.82 to 2.85 & $1.53 \pm 0.64$ & 0.72 to 2.85 & 1.69 \\
\hline $\begin{array}{l}\text { ASCRS } \\
\text { average }\end{array}$ & $0.81 \pm 1.09$ & -0.88 to 2.79 & $1.02 \pm 0.87$ & 0.07 to 2.79 & 1.19 \\
\hline
\end{tabular}

Abbreviations: ASCRS, American Society of Cataract and Refractive Surgery, D, diopters; IOL, intraocular lens; SD, standard deviation. 
Table 3 The percentage of eyes within \pm 0.50 diopters, $\pm 1.00 \mathrm{D}$, \pm I.50 D, and $\pm 2.00 \mathrm{D}$ for each method

\begin{tabular}{lllll}
\hline & \multicolumn{4}{l}{ Percentage of eyes within } \\
\cline { 2 - 5 } & $\pm 0.50 \mathrm{D}$ & $\pm 1.00 \mathrm{D}$ & $\pm 1.50 \mathrm{D}$ & $\pm 2.00 \mathrm{D}$ \\
\hline $\begin{array}{l}\text { Average } \\
\text { central power }\end{array}$ & $60.00 \%$ & $60.00 \%$ & $80.00 \%$ & $100 \%$ \\
$\begin{array}{l}\text { Humphrey } \\
\begin{array}{l}\text { Atlas I-4 } \\
\text { ASCRS } \\
\text { average }\end{array}\end{array}$ & $0.00 \%$ & $46.67 \%$ & $86.67 \%$ & $100 \%$ \\
\hline
\end{tabular}

Abbreviations: ASCRS, American Society of Cataract and Refractive Surgery, D, diopters.

Our results showed that the average central power method and ASCRS average were more accurate than the Humphrey Atlas method with respect to mean arithmetic and absolute IOL prediction errors, variance, and the percentage of outcomes within \pm 0.50 and $\pm 1.00 \mathrm{D}$. Although the average central power had a smaller mean IOL prediction error and a larger percentage of patients within $\pm 0.50 \mathrm{D}$, we consider the ASCRS average to be more useful because it has a smaller variance and a higher percentage of outcomes within $\pm 1.00 \mathrm{D}$. A smaller variance indicates a better consistency of IOL prediction, which leads to increased confidence in that prediction.

In this study, $60 \%$ of eyes using the average central power method, $46.7 \%$ of eyes using the ASCRS average, and $0 \%$ of eyes using the Humphrey Atlas method ended up within \pm 0.50 D. In comparison, the Packer et al and Awwad et al studies had $80 \%$ and $87.5 \%$ of outcomes, respectively, within \pm 0.50 D. In our study, the average central power and Humphrey Atlas methods, and the ASCRS average, all produced mean arithmetic IOL prediction errors that were positive $(0.54 \mathrm{D}, 1.10 \mathrm{D}$, and $0.81 \mathrm{D}$, respectively), leading to hyperopic outcomes. Therefore, if emmetropia is desired, we recommend adding $0.50 \mathrm{D}$ to $1.00 \mathrm{D}$ to the $\mathrm{IOL}$ power

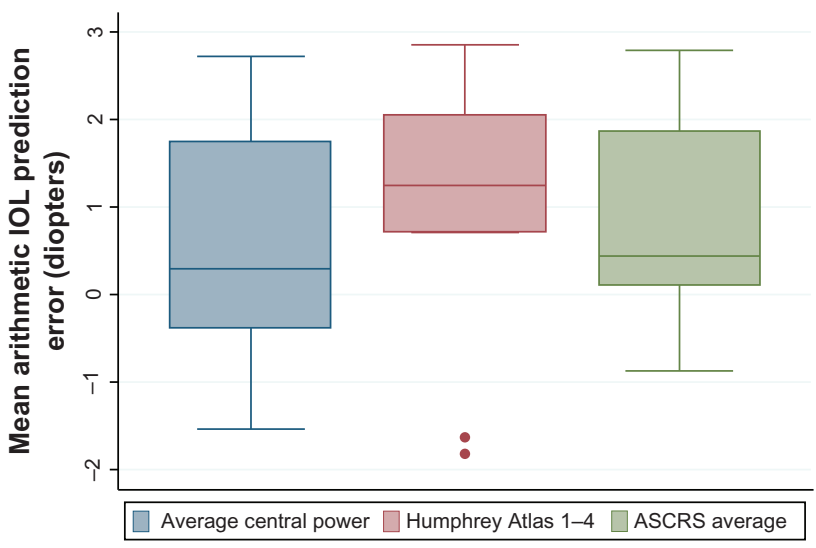

Figure I Boxplot of IOL power prediction errors for each method. Abbreviations: ASCRS, American Society of Cataract and Refractive Surgery; IOL, intraocular lens. prediction of the average central power method and $1.00 \mathrm{D}$ to $1.50 \mathrm{D}$ to the IOL power predictions of the Humphrey Atlas method and ASCRS average. Using the assumption that $1.00 \mathrm{D}$ of IOL prediction error produces $0.70 \mathrm{D}$ of refractive error, ${ }^{14}$ we can deduce that $0.50 \mathrm{D}, 1.00 \mathrm{D}$, and $1.50 \mathrm{D}$ of IOL power leads to approximately $0.35 \mathrm{D}, 0.70 \mathrm{D}$, and $1.05 \mathrm{D}$ of refractive power, respectively.

Several physicians have made the clinical observation that an increase in the number of radial keratotomy incisions increases the probability of a hyperopic outcome after cataract surgery, but there is no consensus on the amount of hyperopia each additional radial keratotomy incision produces. ${ }^{16} \mathrm{~A}$ linear regression analysis of our data did not reveal any significant correlation between the number of radial keratotomy incisions and post-cataract outcomes, likely due to a small sample size. Larger studies are needed to find statistical significance after stratification based on the number of radial keratotomy incisions. Another study limitation was our lack of access to the EyeSys 3000 Corneal Atlas, requested by the ASCRS calculator. This decreased the amount of formulae from the calculator we were able to evaluate. However, many ophthalmologists do not routinely use the EyeSys 3000 Corneal Atlas, so our results may be more representative of most clinical practices.

In conclusion, we consider the ASCRS IOL calculator for eyes with prior radial keratotomy to be an easily accessible and valuable tool. Our analysis showed that in comparison with the average central power and Humphrey Atlas methods alone, the average of these two methods was more accurate. This ASCRS average demonstrated a smaller variance and a higher percentage of outcomes within $\pm 1.00 \mathrm{D}$. We recommend using the ASCRS average with the addition of $1.00 \mathrm{D}$ to $1.50 \mathrm{D}$ to the IOL power prediction. However, larger studies are needed to validate these results.

\section{Acknowledgment}

Funding for this work was received from the Research to Prevent Blindness Foundation, New York, NY.

\section{Disclosure}

The authors have no financial interests in any materials or products discussed in the manuscript or any other disclosures.

\section{References}

1. Choi DM, Thompson RW Jr, Price FW Jr. Incisional refractive surgery. Curr Opin Ophthalmol. 2002;1:237-241.

2. Waring GO, Lynn MJ, McDonnell PJ, and the PERK Study Group. Results of the Prospective Evaluation of Radial Keratotomy (PERK) study 10 years after surgery. Arch Ophthalmol. 1994;112:1298-1308. 
3. Linebarger EJ, Hardten DR, Lindstrom RL. Laser-assisted in situ keratomileusis for correction of secondary hyperopia after radial keratotomy. Int Ophthalmol Clin. 2000;40:125-132.

4. Chen L, Mannis MJ, Salz JJ, Garcia-Ferrer FJ, Ge J. Analysis of intraocular lens power calculation in post-radial keratotomy eyes. J Cataract Refract Surg. 2003;29:65-70.

5. Packer M, Brown LK, Hoffman RS, Fine IH. Intraocular lens power calculation after incisional and thermal keratorefractive surgery. J Cataract Refract Surg. 2004;30:1430-1434.

6. Celikkol L, Pavlopoulos G, Weinstein B, et al. Calculation of intraocular lens power after radial keratotomy with computerized videokeratography. Am J Ophthalmol. 1995;120:739-750.

7. Lyle AW, Jin GJ. Intraocular lens power prediction in patients who undergo cataract surgery following previous radial keratotomy. Arch Ophthalmol. 1997;115:457-461.

8. Hoffer KJ. Clinical results using the Holladay 2 intraocular lens power formula. J Cataract Refract Surg. 2000;26:1233-1237.

9. Aramberri J. Intraocular lens power calculation after corneal refractive surgery: Double-K method. J Cataract Refract Surg. 2003;29: 2063-2068
10. Awwad ST, Dwarakanathan S, Bowman W, et al. Intraocular lens power calculation after radial keratotomy: Estimating the refractive corneal power. J Cataract Refract Surg. 2007;33:1045-1050.

11. Hill W, Wang L, Koch D. IOL power calculator for eyes with prior RK. Available from: http://iol.ascrs.org/. Accessed 14 July 2011.

12. Holladay JT, Hill WE, Steinmueller A. Corneal power measurements using Scheimpflug imaging in eyes with prior corneal refractive surgery. $J$ Cataract Refract Surg. 2009;25:862-868.

13. Wang L, Hill WE, Koch DD. Evaluation of intraocular lens power prediction methods using the American Society of Cataract and Refractive Surgeons post-keratorefractive intraocular lens power calculator. $J$ Cataract Refract Surg. 2010;36:1466-1473.

14. Feiz V, Mannis MJ, Garcia-Ferrer F, et al. Intraocular lens power calculation after laser in situ keratomileusis for myopia and hyperopia: A standardized approach. Cornea. 2001;20:792-797.

15. Hill W, Wang L, Koch D. ASCRS IOL power calculators. Available from: http://iol.ascrs.org/. Accessed July 10, 2011.

16. Dell SJ, Koch DD, Mackool RJ, Masket S, Shultz MC, Woodhams JT. Assessing post-RK eyes. Cataract and Refractive Surgery Today. 2010;19-20.
Clinical Ophthalmology

\section{Publish your work in this journal}

Clinical Ophthalmology is an international, peer-reviewed journal covering all subspecialties within ophthalmology. Key topics include: Optometry; Visual science; Pharmacology and drug therapy in eye diseases; Basic Sciences; Primary and Secondary eye care; Patient Safety and Quality of Care Improvements. This journal is indexed on

Submit your manuscript here: http://www.dovepress.com/clinical-ophthalmology-journal

\section{Dovepress}

PubMed Central and CAS, and is the official journal of The Society of Clinical Ophthalmology (SCO). The manuscript management system is completely online and includes a very quick and fair peer-review system, which is all easy to use. Visit http://www.dovepress.com/ testimonials.php to read real quotes from published authors. 